
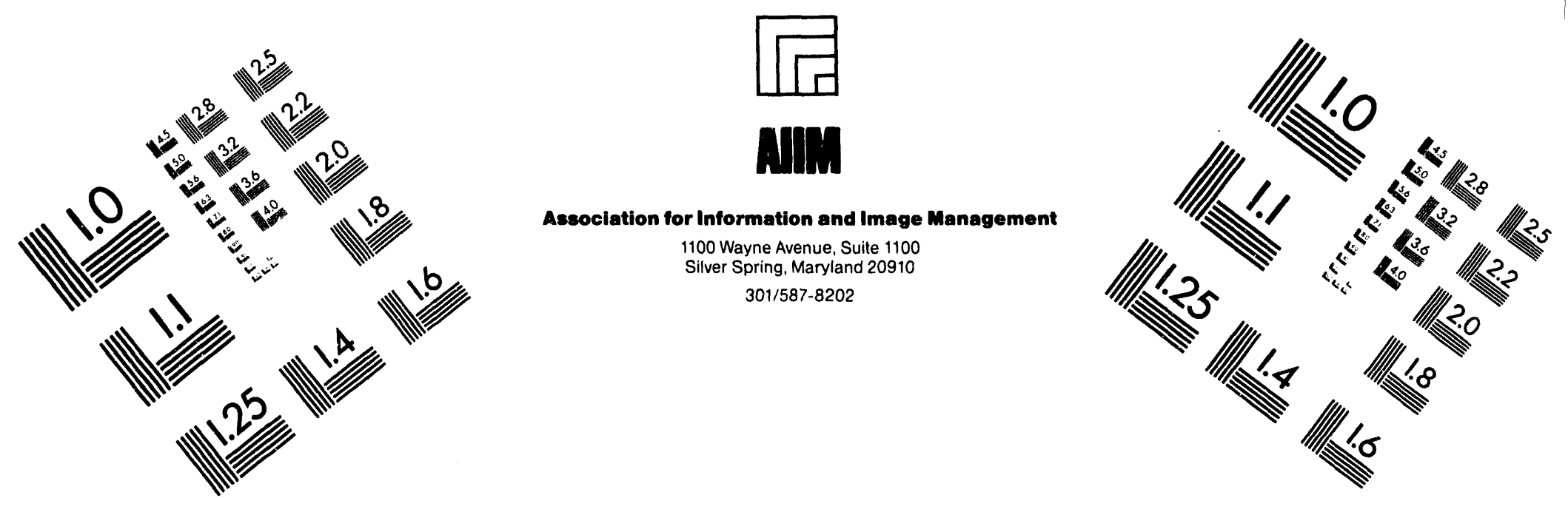

\title{
Centimeter
}

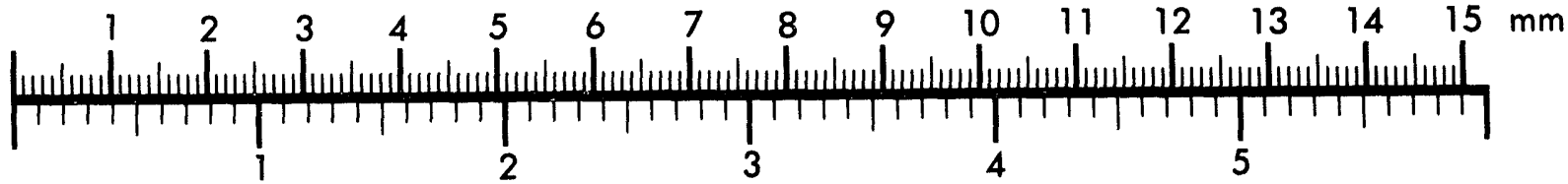

Inches
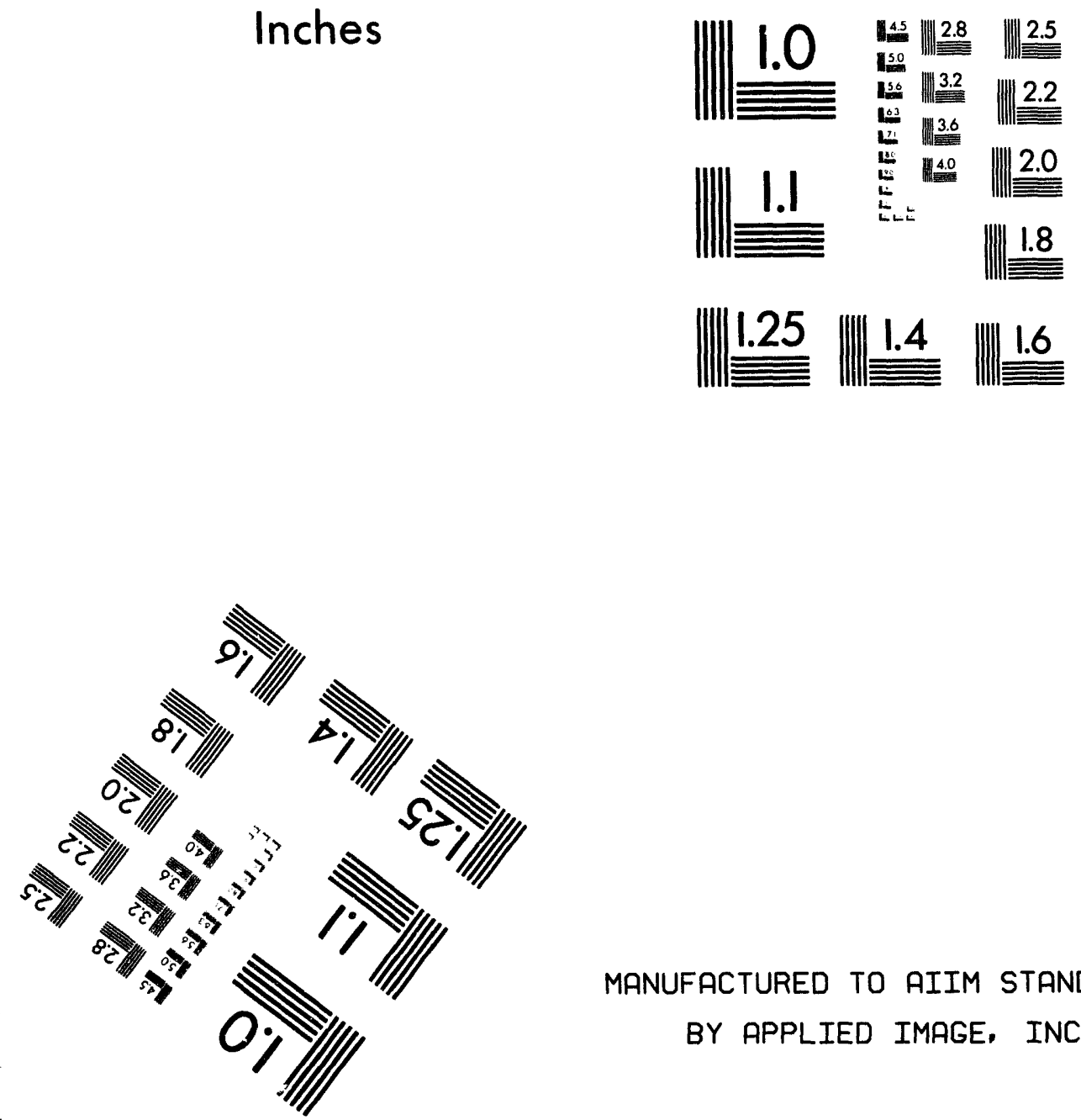

MANUFACTURED TO AIIM STANDARDS

BY APPLIED IMAGE, INC.

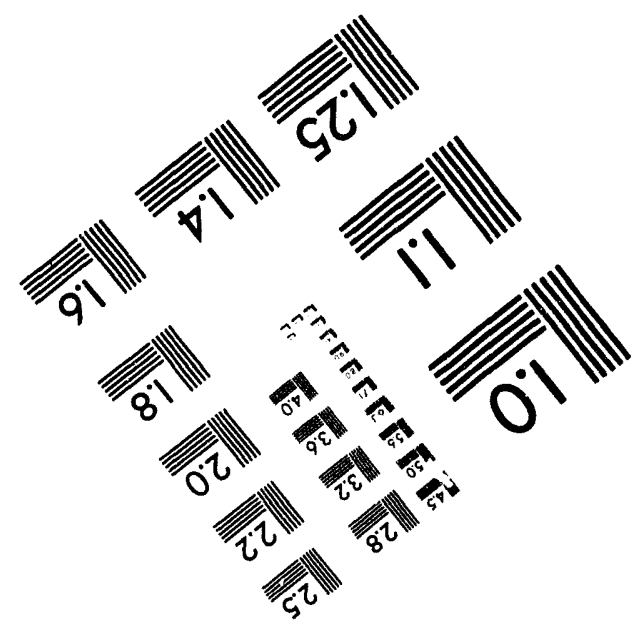



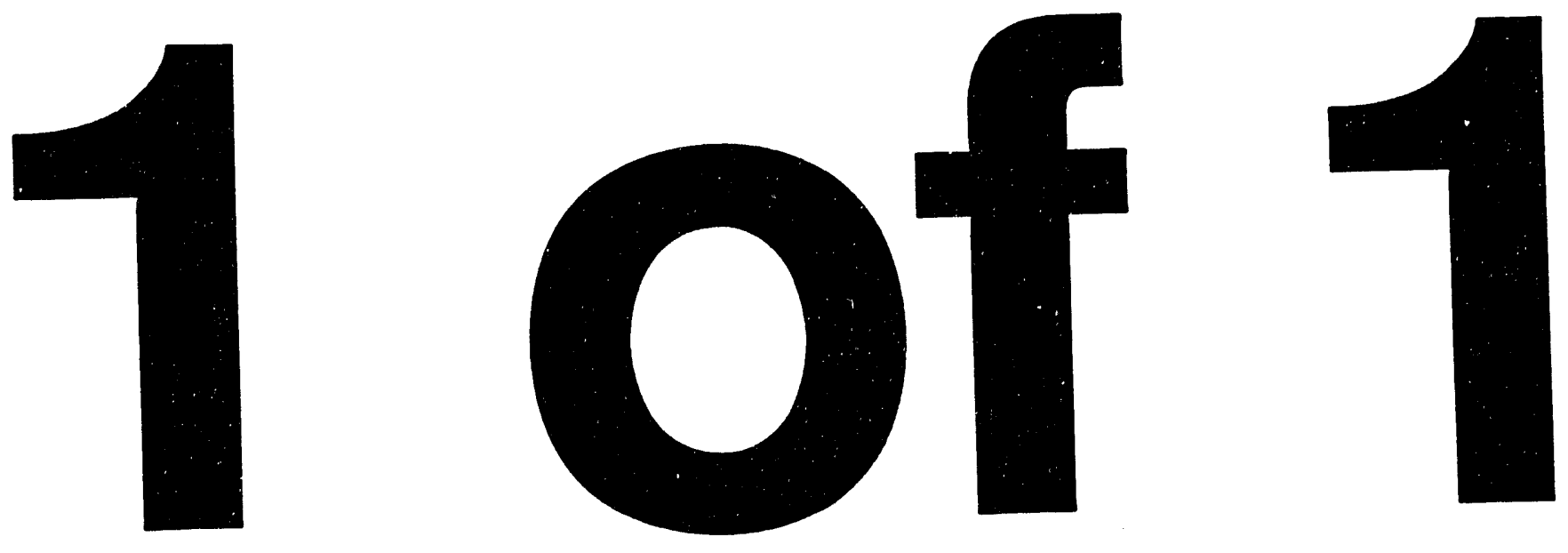
DOE Report Number

Title

Subt it le

Personal Author

Contractor's Name and Address

Reporting Period

DOE Sponsoring and Contract Number
DOE/ER/14320-2

\section{NEW HIGH TEMPERATURE PLASMAS AND SAMPLE INTRODUCTION SYSTEMS FOR ANALYTICAL ATONIC EMISSION AND MASS SPECTROAETRY}

\section{Progress Report}

Akbar Montaser
The George Washington University Office of Sponsored Research Washington, D.C. 20052

January 1, 1994-December 31, 1994

PREPARED FOR THE U.S. DEPARTMENT OF ENERGY UIDER GRANT NO. DE-FG02-93ER14320

\section{DISCLAIMER}

This report was prepared as an account of work sponsored by an agency of the United States Government. Neither the United States Government nor any agency thereof, nor any of their employees, makes any warranty, express or implied, or assumes any legal liability or responsibility for the accuracy, completeness, or usefulness of any information, apparatus, product, or process disclosed, or represents that its use would not infringe privately owned rights. Reference herein to any specific commercial product, process, or service by trade name, trademark, manufacturer, or otherwise does not necessarily constitute or imply its endorsement, recommendation, or favoring by the United States Government or any agency thereof. The views and opinions of authors expressed herein do not necessarily state or reflect those of the United States Government or any agency thereof.

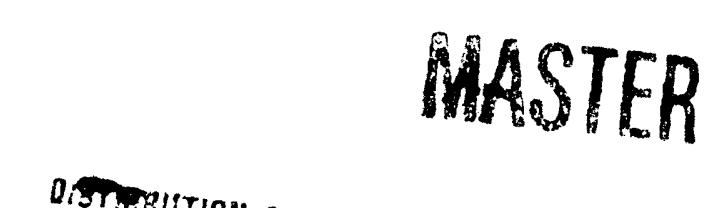

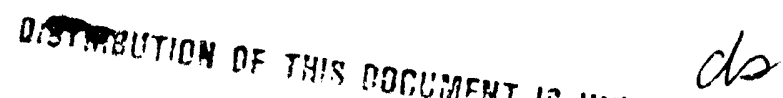




\section{Table of Contents}

Subject

1. PURPOSE AND SCOPE 1

2. TECHNICAL PROGRESS FROM JANUARY-1994 THROUGH DECEMBER-1994 2

3. TECHNICAL PROGRESS EXPECTED NEXT YEAR 6

4. REFERENCES CITED $\quad 7$

5. DOE-SPONSORED PUBLICATIONS AND PAPERS PRESENTED DURING 1993-94 8

6. TIME DEVOTED TO THE PROJECT AND DEVELOPMENT OF HUMAN RESOURCES 9 


\section{PROGRESS REPORT}

In this Report, we summarize our DOE-sponsored research activities over the period January 1994 December 1994. Detailed description of our investigations are outlined in a total of 12 reprints and preprints that accompany this Report. During this period, many excellent reviews were published for the second edition of our 1017-page book (Inductively Coupled Plasmas in Analytical Atomic Spectrometry). For example, Professor D. Beauchemin and co-authors have referred (see Fundamental Review in Anal. Chem. 1994, 66, 462R-499R) to our book as "probably the most important contribution to the field" and the "ICP bible". Undoubtedly, PI's contribution to this significant book would not have been possible without the support from the Department of Energy.

Our DOE-sponsored research this year led to industrial collaborations with three firms: 1) IBM Corporation, 2) Perkin-Elmer/Sciex Corporation, and 3) J. E. Meinhard Associates. The nature of these collaborative studies are briefly discussed in this Report. The benefits of such joint University-Industry efforts for the success of our projects and in the training of our students are obvious, considering the current preoccupation of Congress and the Administration with shifting research funds toward national priorities. As in the past, Professor J. Mostaghimi (University of Toronto) and us collaborated on the computer modeling of plasma discharges.

\section{PURPOSE AND SCOPE}

This research follows a multi-faceted approach, from theory to practice, to the investigation and development of novel helium plasmas, sample introduction systems, and diagnostic techniques for atomic and mass spectrometries. During the period January 1994 - December 1994, four major sets of challenging research programs were addressed that each included a number of discrete but complementary projects:

1. The first program is concerned with fundamental and analytical investigations of novel atmosphericpressure helium inductively coupled plasmas (He ICPs) that are suitable for the atomization-excitationionization of elements, especially those possessing high excitation and ionization energies, for the purpose of enhancing sensitivity and selectivity of analytical measurements.

2. The second program includes simulation and computer modeling of He ICPs. The aim is to ease the hunt for new helium plasmas by predicting their structure and fundamental and analytical properties, without incurring the enormous cost for extensive experimental studies.

3. The third program involves spectroscopic imaging and diagnostic studies of plasma discharges to instantly visualize their prevailing structures, to quantify key fundamental properties, and to verify predictions by mathematical models.

4. The fourth program entails investigation of new, low-cost sample introduction systems that consume 
micro- to nanoliter quantity of sample solution in plasma spectrometries. A portion of this research involves development and applications of novel diagnostic techniques suitable for probing key fundamental properties of aerosol prior to and after injection into high-temperature plasmas. These efforts, still in progress, collectively offer promise of solving singularly difficult analytical problems that either exist now or are likely to arise in the future in the various fields of energy generation, environmental pollution, material science, biomedicine and nutrition.

\section{TECHNICAL PROGRESS FROM JANUARY-1994 THROUGH DECEMBER-1994.}

Clearly, the extent of technical progress is partly tied to the support level. We should emphasize that our level of support have been consistently below the national average! For example, the funds $(\$ 77.5 \mathrm{~K})$ provided by DOE for Year I of this research were approximately one-half of the requested level. Similarly, the funds ( $\$ 77.5)$ furnished by DOE for Year II were approximately $\$ 30 \mathrm{~K}$ less than the requested level. Note that the funding levels were controlled by the prevailing economic situation rather than comments by the reviewers. In fact, the DOE reviewers commented that our proposed budget was very reasonable! An urgent appeal by the PI prompted DOE to provide a supplement of $\$ 15 \mathrm{~K}$ in August 1994 for Year II of this research. However, the supplement was subsequently reduced to approximately $\$ 12 \mathrm{~K}$ due to budget cut. These budgetary restrictions collectively have prevented us from pursuing a number of promising studies on sample introduction systems and direct optical sampling of ultraviolet radiation from He ICP. Work in other areas also had to be curtailed. We are hoping to acquire sufficient funds from DOE for these projects next year.

Despite the cited difficulties, we have made excellent progress in a number of our projects thanks to the efforts of PI's six graduate students. This year, one of PI's graduate students (Mr. M. Cai) received a national Award (the 1994 Winter Conference on Plasma Spectrochemistry Award) for his contributions to the DOE-sponsored research. Since 1991, three Ph.D students from this group have received national and international awards on our DOE-sponsored research. Thus, we are producing high-quality young researchers in areas of critical needs related to environmental issues, advanced instrumentation, and energy generation.

Our studies on helium inductively coupled plasma-mass spectrometry (He ICP-MS) have had significant progress since last year, i.e., we have improved detection limits for certain metals in He ICP by two orders of magnitude compared to our previous results published last year [ 1] using our prototype ICP-MS instrument. This achievement is attributed to several new findings/predictions that resulted from fundamental studies of the plasma through computer modeling and simulation. As stated in previous Annual Reports, one of the most serious obstacles in using a He ICP as an ion source for mass spectrometry is the secondary discharge or the pinch discharge. Our studies [1] and those by Koppenaal and Quinton [2] have shown that the interface-related discharge is strikingly stronger in He ICP-MS compared to that reported for Ar ICP-MS [3-13] when crystalcontrolled RF generators are used to form plasmas. We have confirmed this observation by computer modeling and simulation of He ICP. The data in Figure 1 (top panel) show that the strength of the predicterl electric 

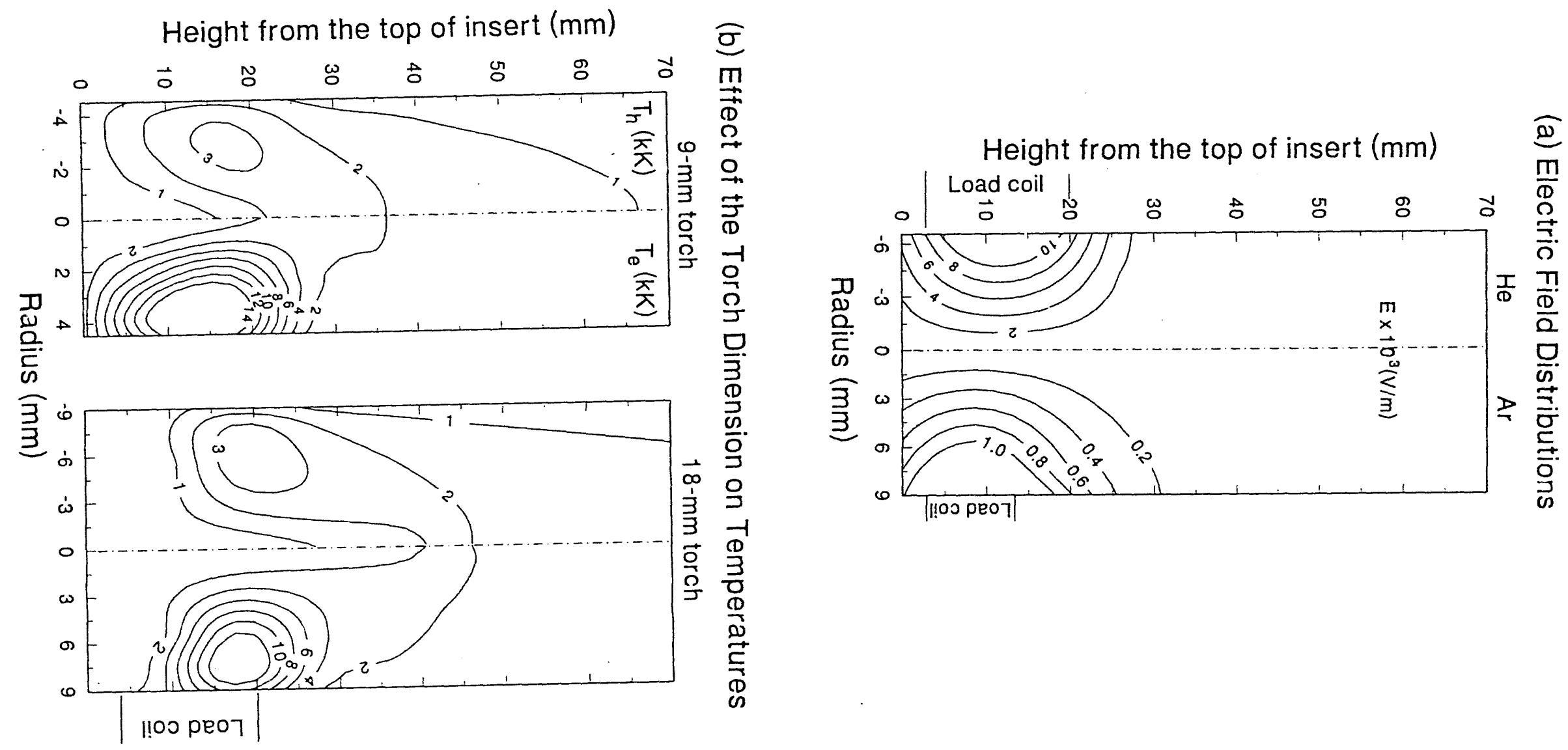
field is approximately one order of magnitude larger for our most-often used He ICP (13-mm id torch) than that in the commonly-used Ar ICP (18-mm id torch). In general, the presence of this secondary discharge results in the formation of doubly-charged species, boosts the spread of ion kinetic energies, produces a prominent ion signal due to nickel, and reduces the lifetime of the nickel sampler. Further, we have now established [1] that almost all approaches used to reduce or eliminate the pinch discharge for Ar ICP-MS [2-13] are ineffective in the case of the He ICP-MS.

In view of the above statements, how did we reduce the secondary discharge in He ICP-MS? In one approach, we explored the utility of a Colpitts-based, free-running generator in our He ICP-MS studies. One notable feature of free-running generator is the ease with which plasma is formed over the wide range of operating condition, especially under the balanced circuit condition required for ICP-MS studies. This condition simplifies the extraction of ions from the helium plasma for delivery to ion optics inside the vacuum chamber of the ICP-MS.

Since last year, we have successfully coupled a 700-W free-running He ICP to our prototype mass spectrometer, and the preliminary results for aqueous samples look promising [14a]. For example, the detection limits for both metals and nonmetals are better or equivalent to our previous results obtained with a fixedfrequency generator, but more importantly, the strength of the secondary discharge has been reduced. Along with these studies, our recent Non-LTE modeling studies [14b] have directed us to fabricate improved He ICP torches for He ICP. The data in Figure 1 (lower panels) show the predicted contour lines for electron temperature $\left(T_{e}\right)$ and beavy-particle temperature $\left(T_{h}\right)$ in a $9-\mathrm{mm}$ torch and an $18-\mathrm{mm}$ torch for He ICP. The important point is the following: the predicted region of maximum temperature in the He ICP is shifted outside the induction coil as the torch diameter is increased. Without getting into the various details, suffice it to mention that our recent use of an 18-mm He ICP torch along with a modified ICP-MS interface currently provide detection limits for metals (Table 1), using an analogue mass detector, that are two orders of magnitude better than our previous results published last year [1]. In short, we are improving the He ICP by our modeling studies. We are confident that much better results can be achieved at a remarkably faster pace if our experimental studies are conducted with a state-of-art ICP-MS instrument rather than our prototype ICPMS instrument.

Table 1. Recent Detection Limits of He ICP-MS ( $\mathrm{pg} / \mathrm{mL}$ ) for Metals Using an analogue mass detector

$\begin{array}{llc}\text { Element } & \text { Isotope } & \text { Detection Limit } \\ \mathrm{Mn} & 55 & 15 \\ \mathrm{Ni} & 58 & 27 \\ \mathrm{Cu} & 63 & 47 \\ \mathrm{Zn} & 64 & 72 \\ \mathrm{~Pb} & 208 & 10\end{array}$


The above preliminary results with He ICP have not distracted us from asking ourselves a number of hard, basic questions: Is a free-running He ICP a better ionization source for mass spectrometry for a large number of elements compared to the fixed-frequency He ICP and why? Is the extent of secondary discharge from an analytically useful plasma greater in He ICP-MS compared to Ar ICP-MS when a free-running generator is used? What extent of symmetry in the electrical component arrangement around the plasma induction coil is essential to ensure that the plasma potential and the resultant ion energies are well controlled and independent of plasma operating conditions in He ICP-MS? How does the design of the plasma torch affect vaporization-atomization-ionization processes in He ICP-MS? What are the critical parameters for achieving complete vaporization-atomization-ionization in He ICP-MS? Are intact particles drawn into the sampling orifice of a He ICP-MS instrument, and what are the conditions for their destruction before analytical measurements? Answers to these and other typical questions cannot be acquired without access to a state-of-art ICP-MS instrument. We plan to submit an instrumentation proposal to DOE and NSF Instrumentation Programs to acquire such an instrument. This is a critical equipment for doing viable research in plasma source mass spectrometry.

Another new avenue of research in He ICP-MS that we began to explore this year involved the study of matrix effects as the result of addition of increasing concentration of $\mathrm{Na}, \mathrm{U}$ and $\mathrm{SO}_{4}{ }^{2 \cdot}$ to solutions containing important elements such as $\mathrm{As}$ and $\mathrm{Br}$ as the analytes [15]. The major observation was that enhancement of $\mathrm{As}$ and $\mathrm{Br}$ signals by $\mathrm{Na}, \mathrm{U}$ and $\mathrm{SO}_{4}{ }^{2}$ did occur, but the enhancement effects could be corrected by the use of Se as an internal standard. To understand the nature of interferences in He ICP-MS, we are currently investigating the influence of the space charge on the observed enhancement effects. This work, conducted in collaboration with Dr. Scott Tanner of Perkin-Elmer/Sciex Corporation, involved modeling and computer simulation of ion trajectories in He ICP-MS. The initial results of these studies should be available next year.

In addition to the cited collaborative studies with Perkin-Elmer/Sciex Corporation, we initiated industrial collaboration with the IBM Corporation (Dr. E. F. Cromwell, Storage System Division, San Jose, CA). In this work, an improved He ICP ion source is coupled with a Mattauch-Herzog multichannel mass spectrometer for fast and simultaneous detection of ions. One of PI's graduate students (Mr. S-H. Nam) spent two summer months at IBM to characterize the use of new He ICP torches with this instrument for elemental analysis. The first results of these unique studies will be available next year [16].

Two new exciting studies were conducted in the area of sample introduction. These studies were partly funded by J. E. Meinhard Associates, Inc. In the first study [17], a new pneumatically-driven, high-efficiency nebulizer (HEN) was explored for argon inductively coupled plasma mass spectrometry (Ar ICPMS) for elemental analysis of aqueous samples. The new nebulizer operates at very low solution uptake rates (10 to 100 $\mu \mathrm{L} / \mathrm{min}$ ). Analytical performance indices for nebulization with the HEN were obtained for three Ar ICPMS systems. These characteristics also were compared to those of typical conventional pneumatic nebulizers (PN) that function at higher solution uptake rates $(1-2 \mathrm{~mL} / \mathrm{min})$. Parts-per-trillion detection limits, similar to those realized by conventional PNs, were obtained for aqueous solution introduction. In general, short-term and long- 
term precision of the HEN for Ar ICPMS were better than the results for the conventional PNs. In short, sample consumption is reduced with the HEN by a factor of 20-25 without sacrificing analytical performance.

Our second study on sample introduction was concerned with the diagnostics of the HEN [18]. Two phase/Doppler instruments (a two- and a four-beam laser light-scattering interferometers) were used for the diagnostic studies of aerosol produced by the HEN. Diagnostic studies involved measurements on primary and tertiary aerosols prior to injection into a high-temperature argon plasma. Simultaneous measurements were conducted on droplet-size and droplet-velocity distributions, size-velocity correlation, span of aerosols, droplet number density, volume flux, and percent volume of aerosol droplets under $8 \mu \mathrm{m}$. The four-beam interferometer (or the 2D Phase/Doppler system) was used to assess the axial- and radial-velocity components of the primary aerosol from the HEN. A broad range of droplet velocities was observed near the nebulizer tip for the primary aerosol, but most tertiary droplets traveled at nearly the same velocity, much slower than the primary droplets. The Sauter mean diameter of the primary aerosol was found to increase both along the centerline of the aerosol pathway and within the boundary of the spray. Importantly, the $D_{3,2}$ of tertiary aerosol generated by the HEN was approximately $2-3 \mu \mathrm{m}$ smaller than that of a conventional pneumatic nebulizer over a wide range of solution uptake rate $(10-1,200 \mu \mathrm{L} / \mathrm{min})$. For the solutions tested, the $D_{3,2}$ of tertiary aerosol from the HEN was not affected significantly by solution viscosity and surface tension.

The better quality of the aerosol from the HEN can lead to additional advantages aside from sample conservation, namely, one should expect better precision, as demonstrated in our anaiytical studies with Ar ICPMS [17], and lower matrix effects when the HEN is used for ICP spectrometry compared to the conventional nebulization at higher uptake rate. Considering that our diagnostic studies were conducted on aerosol prior to introduction into a plasma, it is appropriate to monitor the fate of droplets from this nebulizer in the plasma, and the effects of the acids on the detection power, precision, and accuracy of analytical measurements in argon ICP spectrometries. While this HEN is an efficient nebulizer if argon is used, its utility for nebulization with helium and the characteristics of the resulting aerosol must be established, particularly in view of the interests in the helium-based plasmas [19]. Work in these area are currently in progress in our laboratory.

For the sake of brevity, we now list a number of other studies that have been completed or are still in progress:

1. Our recent imaging studies of He ICP [20] have been extended to the atomic emission investigation of new plasmas formed in new He ICP torches (an 18-mm torch and a 9-mm torch). Operating conditions have been identified for gaseous and aqueous sample injection. As stated earlier, significantly improved results were obtained when the plasma formed in the $18-\mathrm{mm}$ torch was used for He ICP-MS. The plasma in the 9-mm torch was only suitable for He ICP-AES. To reduce noise level associated with plasma rotation, we have just developed an 18-mm linear-flow torch for He ICP. No plasma has been formed in this torch yet.

2. Aside from ICP discharges, our investigation include studies of argon and helium radio frequency glow discharges (RFGD) for direct analysis of solid samples [21]. These plasma were operated successfully 
with RF power generators and impedance matching networks designed for inductively coupled plasmas. A 40.6-MHz RFGD was examined as an ion source for mass spectrometry of conductive and nonconductive samples. Mass spectra were generated at a very low power level (30 W) compared to an ICP source $(1200 \mathrm{~W})$. The forward power, discharge pressure, and sampling distance were found to have significant effects on ion signal intensity. The optimum sampling distance was a function of sample type, discharge gas, and discharge pressure. Ion kinetic energies for some of the most abundant ions in argon and helium RF-GD were determined to be around $5 \mathrm{eV}$ with distributions of 5-7 eV. Major components for non-conductive sample (Ar RFGD) and minor elements for conductive sample (He RFGD) were identified. The He RFGD was not sufficiently intense to sample nonconductive materials for mass spectrometry. Work is in progress for the detection of halogens and nonmetals usiuig a helium glow discharge source. Such a device has potentia ${ }^{*}$ as a detector for chromatographic separation.

3. An electronic paper on the determination of elect a number density $\left(n_{e}\right)$ in plasmas was finalized for publication in Spectrochimica Acta Electronica [22]. The determination of $n_{b}$ was accomplished by least-squares fitting of the entire emission profile or the wing portions of the emission profile of the $\mathrm{H}_{\beta}$ line $(486.13 \mathrm{~nm})$ to the theoretical Stark broadened profiles, compiled at electron temperature 2500 , 5000,10000 and $20000 \mathrm{~K}$. This approach can reduce errors in the determination of $n_{0}$ owing to the structural dip in the center of the Stark profiles depending on $n_{0}$ value. The curve-fitting routine employs an interval-halving algorithm to produce new interpolated Stark profiles, reduces number of iterations and time required for calculation, and allows the calculation of $n_{0}$ to the limits set by instrument spectral resolution and the availability of theoretical spectral data. In addition to $\mathrm{H}_{\beta}$, theoretical profiles also are included for $\mathrm{H}_{\alpha}$ and $\mathrm{H}_{\gamma}$ to illustrate the suitability and drawbacks of these lines for $n_{0}$ estimation.

4) Because of the volume of work conducted and limited funding (see Section 2), there was no opportunity to finalize a number of other reports. These reports address: 1) computer modeling and simulation studies of non-LTE He ICP discharges [14b], 2) modeling and simulation of mixed-gas ICP discharges [23], 3) high-speed video recording of helium and argon ICPs for mass spectrometry [24], and 4) exploration of thimble-frit nebulizer and the humidifier-based ultrasonic nebulizer for direct analysis of environmental samples and food $[25,26]$.

5) As stated earlier, our proposed studies of sample introduction systems were curtailed due the lack of funding. Accordingly, new studies on nozzle-type ultrasonic nebulizer could not be pursued this year.

\section{TECHNICAL PROGRESS EXPECTED NEXT YEAR}

We anticipate that the on-going investigations discussed above will continue or expand for the next year. The results of some of these studies are being prepared in 5 publications (see papers number 13 to 17 in Section 5). In addition, a total of 10 papers were presented at the scientific meeting (4 invited). 
1. S-H. Nam, W. R.L. Masamba, and A. Montaser, Anal. Chem. 65, 2784 (1993).

2. D. W. Koppenaal and L. F. Quinton, J. Anal. At. Spectrom.3, 667 and 1144 (1988).

3. M. Cai, A. Montaser, and J. Mostaghimi, Spectrochim. Acta, 48B, 789 (1993).

4. D. J. Douglas, U.S. Patent Number 4682026 (1987).

5. (a) D. J. Douglas and J. B. French, Spectrochim. Acta, 41B, 197 (1986), (b) J. E. Fulford and D. J. Douglas, Appl. Spectrosc. 40, 971 (1986).

6. R. S. Houk, J. K. Schoer, and J. S. Crain, J. Anal. At. Spectrom. 2, 283 (1987).

7. N. Jakubowski, B. J. Raeymaekers, J. A. C. Broekaert, and D. Stuewer, Spectrochim. Acta, 44B, 219 (1989).

8. J.A. Olivares and R.S. Houk, Appl. Spectrosc. 39, 1070 (1985).

9. A. L. Gray, J. Anal. At. Spectrom. 1, 247 (1986).

10. A. L. Gray, J. Anal. At. Spectrom. 2, 13 (1987).

11. R. C. Hutton and A. N. Eaton, J. Anal. At. Spectrom. 2, 595 (1987).

12. K. Miseki, U. S. Patent. No. 4804838 (Feb.14, 1989).

13. D. J. Douglas, Fundamental Aspects of Inductively Coupled Plasma-Mass Spectrometry, in INDUCTIVELY COUPLED PLASMAS IN ANALYTICAL ATOMIC SPECTROMETRY, A. Montaser and D. W. Golightly, Eds, VCH, 2nd Ed., New York, NY, 1992.

14. (a) L. A. Iacone, W. R. L. Masamba, S-H. Nam, and A. Montaser, "High-Speed Video Recording of Helium and Argon Inductively Coupled Plasmas for Mass Spectrometry", in preparation for Journal of Anal. At. Spectrom., (b) M. Cai, A. Montaser, and J. Mostaghimi, "A Two-Temperature Model for the Simulation of Atmospheric-Pressure Helium ICPs", in preparation for Spectrochim. Acta, Part B.

15. S-H. Nam, W. R.L. Masamba, and A. Montaser, "Helium Inductively Coupled Plasma-Mass Spectrometry: Studies of Matrix Effects and the Determination of Arsenic and Selenium in Urine", Spectrochim. Acta, in press.

16. S-H. Nam, A. Montaser, and E. F. Cromwell, "Helium Inductively Coupled Plasma with a Multichannel Mattauch-Herzog Mass Spectrometer", to be presented at 1995 Pittsburgh Conference, New Orleans.

17. S-H. Nam, J-S. Lim, and A Montaser, "High Efficiency Nebulizer for Argon Inductively Coupled Plasma Mass Spectrometry", submitted to J. Anal. At. Spectrom.

18. H. Liu and A. Montaser "Phase-Doppler Diagnostic Studies of Primary and Tertiary Aerosols Produced by a New High .Efficiency Nebulizer", Anal. Chem. in press.

19. (a) A. Montaser, K. D. Ohls, and D. W. Golightly, Inductively Coupled Plasmas in Gases Other Than Argon. In "Inductively Coupled Plasmas in Analytical Atomic Spectrometry," A. Montaser and D. W. Golightly, Eds, VCH, New York, 2nd Edition, 1992, (b) P.G. Brandl, J. W. Carnahan, Spectrochim. Acta 49B, 105 (1994) and references therein.

20. A. Montaser, A. M. Boyes, M. Cai, C. Hsiech, and H. Zhang, "Spectroscopic Imaging of AtmosphericPressure Helium ICP Discharges", SPIE, Optical Spectroscopic Techniques and Instrumentation for Atmospheric and Space Research, 1994, in press.

21. H. Zhang and A. Montaser, "Radio Frequency-Powered Glow Discharge Mass Spectrometry at 40.6 MHz for Direct Analysis of Solid Samples", submitted to J. Anal. At. Spectrom.

22. H. Zhang, I. Ishii, C. Hsiech, Zongfu Zeng, and A. Montaser;"Revised, Fast, Flexible Algorithms for Determination of Electron Number Densities in Plasma Discharges", Spectrochim. Acta Electronica, in press.

23. M. Cai, A. Montaser, and J. Mostaghimi, "Modeling and Simulation of Argon-Nitrogen and ArgonOxygen Inductively Coupled Plasmas", in preparation for Spectrochim. Acta, Part B.

24. H. Liu, S. P. Dolan, and A. Montaser, "Application of a Disposable Thimble Frit Nebulizer for the Direct Analysis of Water Samples and Food", in preparation for J. Anal. At. Spectrom.

25. H. Liu, S. P. Dolan, and A. Montaser, "Evaluation of a Low-Cost Humidifier-Based Ultrasonic Nebulizer for Direct Elemental Analysis of Environmental Samples by ICP-AES", in preparation for J. Anal. At. Spectrom. 
5. DOE-SPONSORED PUBLICATIONS AND PAPERS PRESENTED DURING 1993-94

\section{A) List of papers published, in press, submitted, or in preparation:}

1. A. Montaser, Guest Editor for Mermet Honor Issue on "Research and Practical Spectrochemical Analysis", Spectrochim. Acta, 48B , Issues 6/7 (1993).

2. M. Cai, A. Montaser, and J. Mostaghimi, Spectrochim. Acta, 48B, 789 (1993).

3. R. H. Clifford, H. Tan, H. Liu, A. Montaser, F. Zarrin, and P. Keady, "Submicron Particle-Size Measurements with Electromobility Techniques: Comparison of Aerosol from Thermospray, Ultrasonic, Pneumatic, and Frit-Type Nebulizers"; Spectrochim. Acta, 48B, 1221 (1993).

3. S-H. Nam, W. R.L. Masamba, and A. Montaser, "Investigation of Helium Inductively Coupled PlasmaMass Spectrometry for the Detection of Metals and Nonmetals in Aqueous Solutions, Anal. Chem. 65, 2784 (1993).

4. M Cai, I. Ishii, R. H. Clifford, A. Montaser, B. A. Palmer and L. R. Layman, "Fundamental Properties of Helium Inductively Coupled Plasmas with High-Resolution Fourier Transform Spectrometry", Spectrochim. Acta, in press.

5. I. Ishii, M. Cai, A. Montaser, B. A. Palmer and L. R. Layman, "Rotational Temperatures of Argon-Nitrogen ICP Discharges Measured by High-Resolution Fourier Transform Spectrc,metry", Spectrochim. Acta, in press.

6. H. Zhang, I. Ishii, C. Hsiech, Zongfu Zeng, and A. Montaser;"Revised, Fast, Flexible Algorithms for Determination of Electron Number Densities in Plasma Discharges", Spectrochim. Acta Electronica, in press.

7. H. Liu and A. Montaser "Phase-Doppler Diagnostic Studies of Primary and Tertiary Aerosols Produced by a New High-Efficiency Nebulizer", Anal. Chem. in press.

8. A. Montaser, A. M. Boyes, M. Cai, C. Hsiech, and H. Zhang, "Spectroscopic Imaging of AtmosphericPressure Helium ICP Discharges", SPIE, Optical Spectroscopic Techniques and Instrumentation for Atmospheric and Space Research, 1994, in press.

9. S-H. Nam, W. R.L. Masam ba, and A. Montaser, "Helium Inductively Coupled Plasma-Mass Spectrometry: Studies of Matrix Effects and the Determination of Arsenic and Selenium in Urine", Spectrochim. Acta, in press.

10. R. L. Van Hoven, S-H. Nam, A. Montaser, M. W. Doughten, and A. F. Dorrzapf, Jr. "A Novel Sampling Cell for Spark Ablation-Inductively Coupled Plasma Mass Spectrometry of Fire Assay Beads", submitted to Spectrochim. Acta.

11. S-H. Nam, J-S. Lim, and A Montaser, "High Efficiency Nebulizer for Argon Inductively Coupled Plasma Mass Spectrometry", submitted to J. Anal. At. Spectrom.

12. H. Zhang and A. Montaser, "Radio Frequency-Powered Glow Discharge Mass Spectrometry at 40.6 $\mathrm{MHz}$ for Direct Analysis of Solid Samples", submitted to J. Anal. At. Spectrom.

13. H. Liu, R. H. Clifford, S. P. Dolan, and A. Montaser, "A Low-Cost, Demountable Frit Nebulizer for Atomic Spectrometry"; in preparation for J. Anal. Atom. Spectrom.

14. L. A. Iacone, W. R. L. Masamba, S-H. Nam, and A. Montaser, "High-Speed Video Recording of Helium and Argon Inductively Coupled Plasmas for Mass Spectrometry", in preparation for Journal of Anal. At. Spectrom.

15. A. Montaser, "Helium ICP Discharges: Potentials and Challenges", an invited review article for Spectrochim. Acta.

16. H. Liu, S. P. Dolan, and A. Montaser, "Evaluation of a Low-Cost Humidifier-Based Ultrasonic Nebulizer for Direct Elemental Analysis of Environmental Samples by ICP-AES", in preparation for J. Anal. At. Spectrom.

17. M. Cai, A. Montaser, and J. Mostaghimi, "A Two-Temperature Model for the Simulation of Atmospheric-Pressure Helium ICPs", in preparation for Spectrochim. Acta, Part B.

18. M. Cai, A. Montaser, and J. Mostaghimi, "Modeling and Simulation of Argon-Nitrogen and ArgonOxygen Inductively Coupled Plasmas", in preparation for Spectrochim. Acta, Part B. 
B) List of presentations at scientiñc meetings in 1994:1.

1. S-H. Nam, L. Iacone, and A. Montaser, Mass Spectrometry of Helium ICP Discharges with FixFrequency and Free-Running Generators", Presented at the 1994 Pittsburgh Conference, Chicago, III,March 1994.

2. H. Liu, R. H. Clifford, S. P. Dolan, and A. Montaser, "A Demountable Thimble Frit Nebulizer for ICPAES", Presented at the 1994 Pittsburgh Conference, Chicago, Ill, March 1994.

3. M. Cai, H. Zhang, and A. Montaser, "Imaging Studies of New Helium ICP Discharges", Presented at the 1994 Pittsburgh Conference, Chicago, III, March 1994.

4. A. Montaser, "Diagnostics and Analytical Characteristics of a High-Efficiency Nebulizer", Invited talk presented at J. E. Meinhard Associates, Inc., Santa Ana, CA, March 1994.

5. A. Montaser, "Sampling and Chemical Analysis of Ground Water: District of Columbia Ground Water Resource Assessment", invited talk at the Department of Consumer and Regulatory Affairs, Government of the District of Columbia, June 8, 1994.

6. A. Montaser, S-H. Nam, H. Liu, and J-S. Lim, "High-Efficiency Nebulization in Plasma Spectrometry: From Fundamentals to Practice", Keynote Lecture presented at the 4Gth Canadian Spectroscopy Conference, Halifax, Nova Scotia, Canada; August 8-10, 1994.

7. A. Montaser, H. Liu, S-H. Nam, and J-S. Lim, "High-Efficiency Nebulization in Plasma Source-M ass Spectrometry: Fundamentals and Analytical Applications", Invited talk at the ACS National Meeting, Washington, DC; August 21-26, 1994.

8. A. M .ntaser, "Helium-Based Plasmas for Analytical Mass Spectrometry: Potentials and Challenges", Invited talk at the 1994 Eastern Analytical Symposium; November 14-17, 1994, Somerset, NJ.

9. A. Montaser and H. Liu, "Phase-Doppler Diagnostic Studies of Primary and Tertiary Aerosols Produced by a New High-Efficiency Nebulizer", presented at the FACSS Meeting, St. Louis, Missouri, October 1994.

10. S-H. Nam, J-S. Lim, and A. Montaser, "A Critical Evaluation of a High-Efficiency Nebulizer for Argon Inductively Coupled Plasma Mass Spectrometry", presented at the FACSS Meeting, St. Louis, Missouri, October 1994.

\section{TIME DEVOTED TO THE PROJECT AND DEVELOPMENT OF HUMAN RESOURCES.}

PI devoted $100 \%$ of his time during two months of summers to this project. During the academic year, PI fulfilled his teaching duties but the remainder of his time was spent on the execution of this project and on the supervision of six graduate students. 

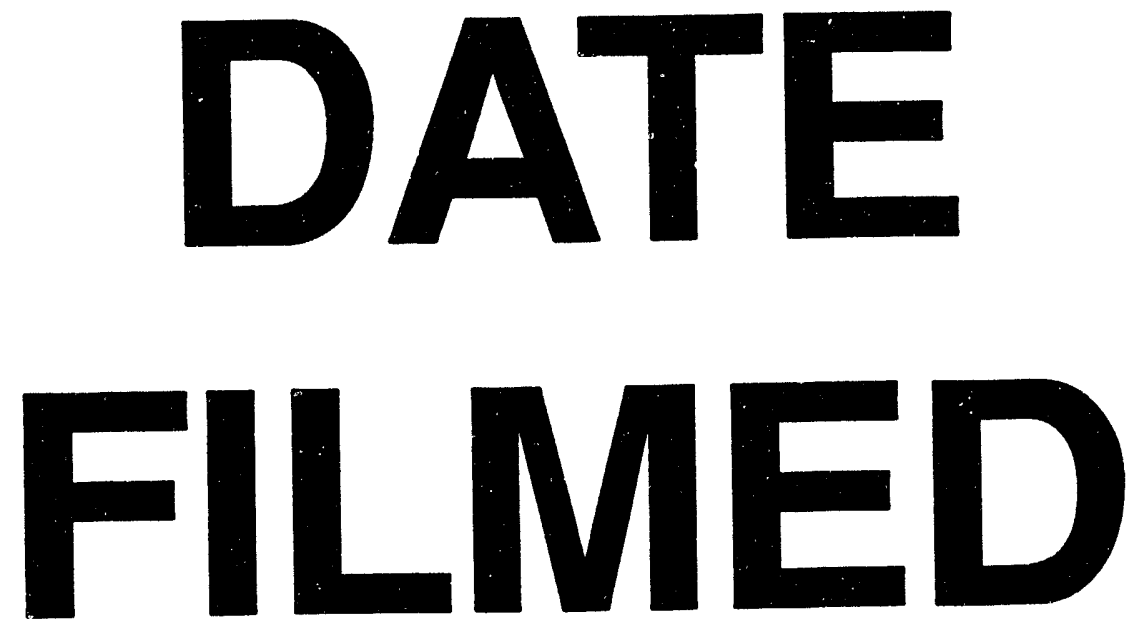

$10 / 5 / 94$
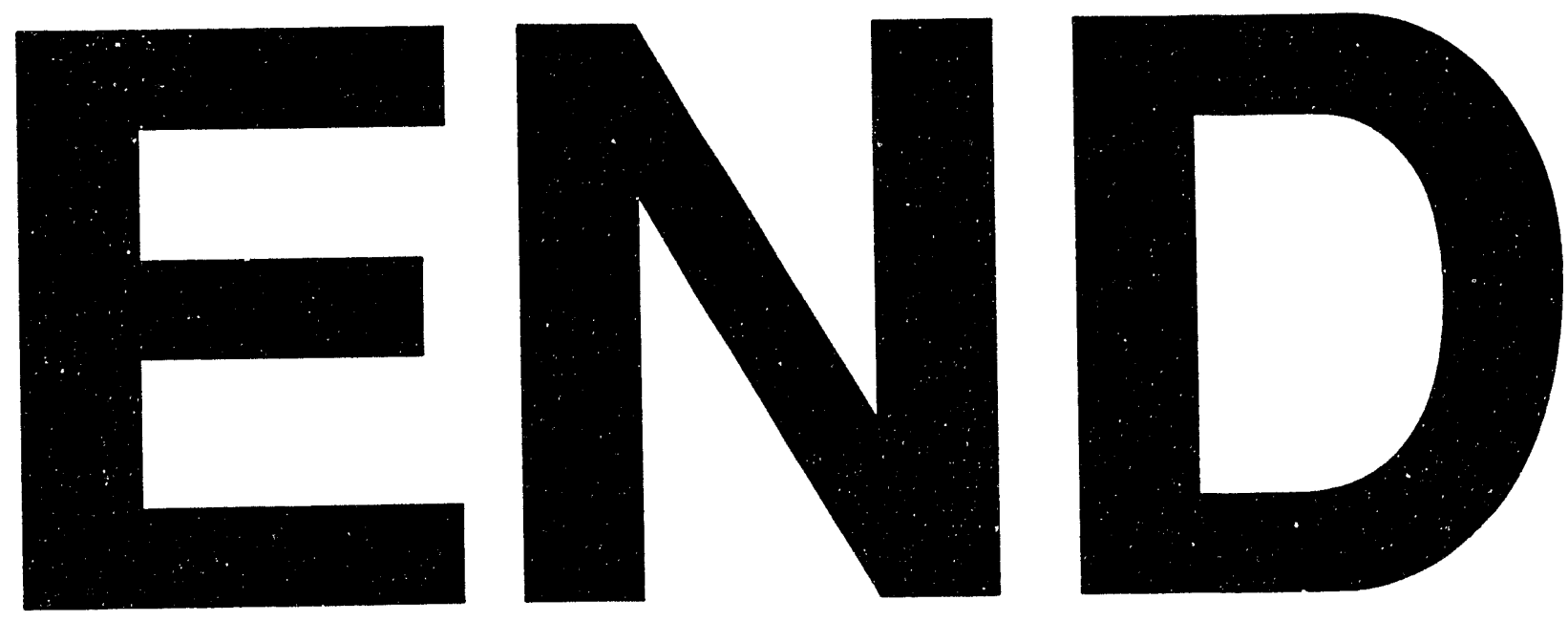
